Purdue University Purdue e-Pubs

2012

\title{
Development of R744 Two Stage Compressor for Commercial Heat Pump Water Heater
}

\author{
Youhei Hotta \\ youhei_hotta@mhi.co.jp \\ Yoshiyuki Kimata \\ Hajime Sato \\ Hiroyuki Kobayashi \\ Hisao Mizuno
}

Follow this and additional works at: https://docs.lib.purdue.edu/icec

Hotta, Youhei; Kimata, Yoshiyuki; Sato, Hajime; Kobayashi, Hiroyuki; and Mizuno, Hisao, "Development of R744 Two Stage Compressor for Commercial Heat Pump Water Heater" (2012). International Compressor Engineering Conference. Paper 2056. https://docs.lib.purdue.edu/icec/2056

This document has been made available through Purdue e-Pubs, a service of the Purdue University Libraries. Please contact epubs@purdue.edu for additional information.

Complete proceedings may be acquired in print and on CD-ROM directly from the Ray W. Herrick Laboratories at https://engineering.purdue.edu/ Herrick/Events/orderlit.html 


\title{
Development of R744 Two Stage Compressor for Commercial Heat Pump Water Heater
}

\author{
Youhei HOTTA $^{1 *}$, Yoshiyuki KIMATA ${ }^{1}$, Hajime SATO $^{2}$, Hiroyuki KOBAYASHI $^{1}$, and Hisao MIZUNO ${ }^{1}$ \\ ${ }^{1}$ Mitsubishi Heavy Industries, Ltd, Air-Conditioning\&Refrigeration Systems Headquarters, \\ 3-1, Asahi, Nishi Biwajima-Cho, Kiyosu, Aichi, 452-8561 JAPAN \\ Phone: +81-52-503-9217, Fax: +81-52-501-5629 \\ E-mail: youhei_hotta@mhi.co.jp \\ ${ }^{2}$ Mitsubishi Heavy Industries, Ltd, Nagoya Research And Development Center, \\ 1-Takamichi, Iwatsuka-Cho, Nakamura-Ku, Nagoya, Aichi, 453-8515 JAPAN \\ Phone: +81-52-412-0599, Fax: +81-52-412-9162 \\ E-mail: hajime_sato@mhi.co.jp
}

\begin{abstract}
A novel CO2 two stage compressor has been developed. The developed compressor equips one rotary and one scroll compression chambers as first and second stage respectively. For efficiency improvement, authors measured the cylinder pressure in each stage and conducted loss classification in the compressor. By adopting appropriate compression type in each stage, and by decreasing critical loss found by measuring the pressure, it resulted in $6 \%$ and $10 \%$ improvement of heating capacity and COP respectively on rated condition, and $25 \%$ and over $50 \%$ improvement on deep-frozen condition compared with conventional single stage compressor. The developed compressor is installed on our newly developed commercial heat pump water heater.
\end{abstract}

\section{INTRODUCTION}

A demand for saving energy has been increasing from the viewpoint of environmental conservation against global warming. In the field of heat pump system, there is a growing interest in high efficiency heat pump system using natural refrigerant. R744 (CO2) as a working fluid has some good characteristics, low GWP, no toxicity, no flammability and available for high temperature hot water, and various heat pump systems using R744 have been developed so far.

For the purpose of further performance improvement of heat pump systems, authors developed a novel R744 two stage compressor. The new compressor equips two stage compression mechanisms. This had reduced pressure difference in each stage, and as a result, compressor efficiency and reliability has been substantially improved. Furthermore, it has intermediate vapor injection between first and second stage in order to support an economizer cycle. As a result, this new compressor achieved over 30\% improvement in efficiency compared with single stage scroll compressor at high pressure ratio condition.

Authors also developed a commercial heat pump water heater using the developed compressor. One of the issues of heat pump system is the drop of heating capacity under low ambient temperature. However, this system provides a sufficient heating capacity even in the cold area and a high COP over the entire range of operating condition by employing the economizer cycle and the high efficiency two stage compressor.

\section{BASIC STRUCTURE OF DEVELOPED COMPRESSOR}

$\mathrm{CO} 2$ as a working fluid has advantages of low GWP, no toxicity and no flammability and is expected to become one of the alternative refrigerants to current HFC refrigerant in refrigeration and air-conditioning fields. On the other 
hand, $\mathrm{CO} 2$ has high operating pressure and high pressure difference compared with conventional refrigerants. This brings decrease of efficiency and reliability to compressor. Therefore, it is especially important for a development of $\mathrm{CO} 2$ compressor to make a proper selection of its basic structure.

In order to establish a basic structure of the new compressor, number of compression stage, type of compression mechanism and shell pressure are studied. Type of compression is one of the most important factors to determine efficiency and reliability of the compressor. Especially, in the case of multi stage compressor, appropriate selection of compression type based on the operating characteristics in each stage is required. In this study, scroll type and rotary type which are suitable for compressors for small or middle capacity are considered. The shell pressure is also a key factor to determine the compressor performance. In this study, discharge pressure, intermediate pressure and suction pressure are considered as the shell pressure.

Table 1 shows performance comparison by difference of structure. Concerning number of compression stage, pressure difference of $\mathrm{CO} 2$ is several times larger than conventional HFC. This leads to increase of gas leakage and mechanical losses. However, by introducing two stage compression, pressure difference in each stage is decreased by about half compared with single stage. In addition, the new compressor is designed on the assumption that an economizer cycle with intermediate gas injection is employed in order to increase COP and heating capacity. In case of a single stage compressor with intermediate injection, a mixture loss occurs and therefore the compressor efficiency drops because the injection proceeds simultaneously with compression process. On the other hand, two stage compressor has no mixture loss by introducing gas injection between first and second stage. For these reasons, two stage compression is considered to have an advantage over single stage compression.

Table 1: Performance comparison by difference of structure

\begin{tabular}{|c|c|c|c|c|c|c|c|c|c|}
\hline \multirow{2}{*}{$\begin{array}{c}\text { Number } \\
\text { of } \\
\text { stage }\end{array}$} & \multirow{2}{*}{$\begin{array}{c}\text { Shell } \\
\text { pressure } \\
* 1\end{array}$} & \multicolumn{2}{|c|}{$\begin{array}{c}\text { Type of } \\
\text { compression }\end{array}$} & \multirow{2}{*}{$\begin{array}{c}\text { Shell } \\
\text { thickness }\end{array}$} & \multirow{2}{*}{$\begin{array}{c}\text { Gas } \\
\text { injection }\end{array}$} & \multicolumn{2}{|c|}{ Reliability } & \multicolumn{2}{|c|}{ Efficiency } \\
\hline & & $\begin{array}{c}1^{\text {st }} \\
\text { stage }\end{array}$ & \begin{tabular}{|c|}
$2^{\text {nd }}$ \\
stage
\end{tabular} & & & $\begin{array}{c}1^{\text {st }} \\
\text { stage }\end{array}$ & $\begin{array}{c}2^{\text {nd }} \\
\text { stage }\end{array}$ & $\begin{array}{c}1^{\text {st }} \\
\text { stage } \\
\end{array}$ & $\begin{array}{c}2^{\text {nd }} \\
\text { stage }\end{array}$ \\
\hline \multirow{2}{*}{$\begin{array}{l}\text { Single } \\
\text { stage }\end{array}$} & $\mathrm{HP}$ & & & - & - & \multicolumn{2}{|c|}{ - } & \multicolumn{2}{|c|}{ - } \\
\hline & LP & & & + & - & \multicolumn{2}{|c|}{ - } & \multicolumn{2}{|c|}{-} \\
\hline \multirow{9}{*}{$\begin{array}{l}\text { Two } \\
\text { stage }\end{array}$} & $\mathrm{HP}$ & & & - & $\begin{array}{l}+ \\
* 2 \\
\end{array}$ & & & & \\
\hline & \multirow{3}{*}{ MP } & Scroll & Scroll & + & ++ & $\begin{array}{c}+ \\
* 3 \\
-\end{array}$ & $\begin{array}{l}+ \\
* 3 \\
--\end{array}$ & + & ++ \\
\hline & & Scroll & Rotary & + & ++ & ++ & - & + & + \\
\hline & & Rotary & Scroll & + & ++ & ++ & ++ & ++ & ++ \\
\hline & & Rotary & Rotary & + & ++ & ++ & - & ++ & + \\
\hline & \multirow{4}{*}{ LP } & Scroll & Scroll & + & $\begin{array}{l}+ \\
* 2 \\
-\end{array}$ & $\begin{array}{r}+ \\
* 3 \\
-\end{array}$ & $\begin{array}{l}+ \\
* 3 \\
-\end{array}$ & + & ++ \\
\hline & & Scroll & Rotary & + & $\begin{array}{l}+ \\
* 2\end{array}$ & ++ & - & + & + \\
\hline & & Rotary & Scroll & + & + & - & ++ & ++ & ++ \\
\hline & & Rotary & Rotary & + & $\begin{array}{l}+ \\
* 2\end{array}$ & - & - & ++ & + \\
\hline
\end{tabular}

Since the operating pressure of $\mathrm{CO} 2$ is much higher than conventional HFC, the shell pressure has a great impact on the shell thickness and thus compressor weight. The impact grows as the size of compressor becomes larger such as commercial and industrial usages. Because of this, it is effective for lightweight of the compressor to keep the design shell pressure low. For this reason, the discharge pressure shell is excluded from the discussion and only suction and intermediate pressure shells are considered. Meanwhile, two stage compressor usually requires a gas flow passage connecting first and second stage. However, in case of intermediate pressure shell, the compressor 
does not need any connecting passage because the shell itself acts as the passage. Besides, a loss from pressure pulsation in both stages (Yokohama et al., 2008) is considered to be far smaller than that of suction or discharge pressure shell with a connection pipe because there exists sufficient volume between both stages. For these reasons, intermediate pressure is considered to be the best choice as the shell pressure.

In terms of compressor reliability, proper oil supply to sliding parts is one of the basic requirements. For the rotary compressor, it has a vane which divides cylinder into suction and compression chambers. The oil is usually supplied to the vane by pressure difference between the shell and the cylinder. In addition, the vane is pressed to a rolling piston by the pressure difference between them. Therefore, in case that rotary type is selected, the shell pressure must be higher than the cylinder pressure or special oil supply and back pressure mechanisms are required.

In a two stage refrigeration cycle with intermediate gas injection for heat pump water heater, the pressure difference in the second stage is larger than that in the first stage in most cases because of the characteristic of refrigeration cycle. Meanwhile, it is generally known that rotary compressor generally has high efficiency in low pressure difference whereas scroll compressor has high efficiency in high pressure difference. Therefore, a combination of the rotary and the scroll as the first and the second stage respectively is expected to be optimum from the standpoint of compressor efficiency.

Based on the above results, the basic structure of the new compressor is determined as below.

- Two stage compression

- Intermediate pressure shell

- Intermediate gas injection between first and second stage

- Rotary compression mechanism for first stage

- Scroll compression mechanism for second stage

Figure 1 shows the structure of the developed new compressor. The compressor is driven by a brushless DC motor located on the middle of the compressor and has two compression chambers on either side of the motor. The first stage compression chamber, rotary type, is located on the lower side of the motor and connected to a suction pipe through a suction accumulator. The second stage chamber, scroll type, is located on the upper side of the motor and connected to discharge pipe through a discharge chamber.

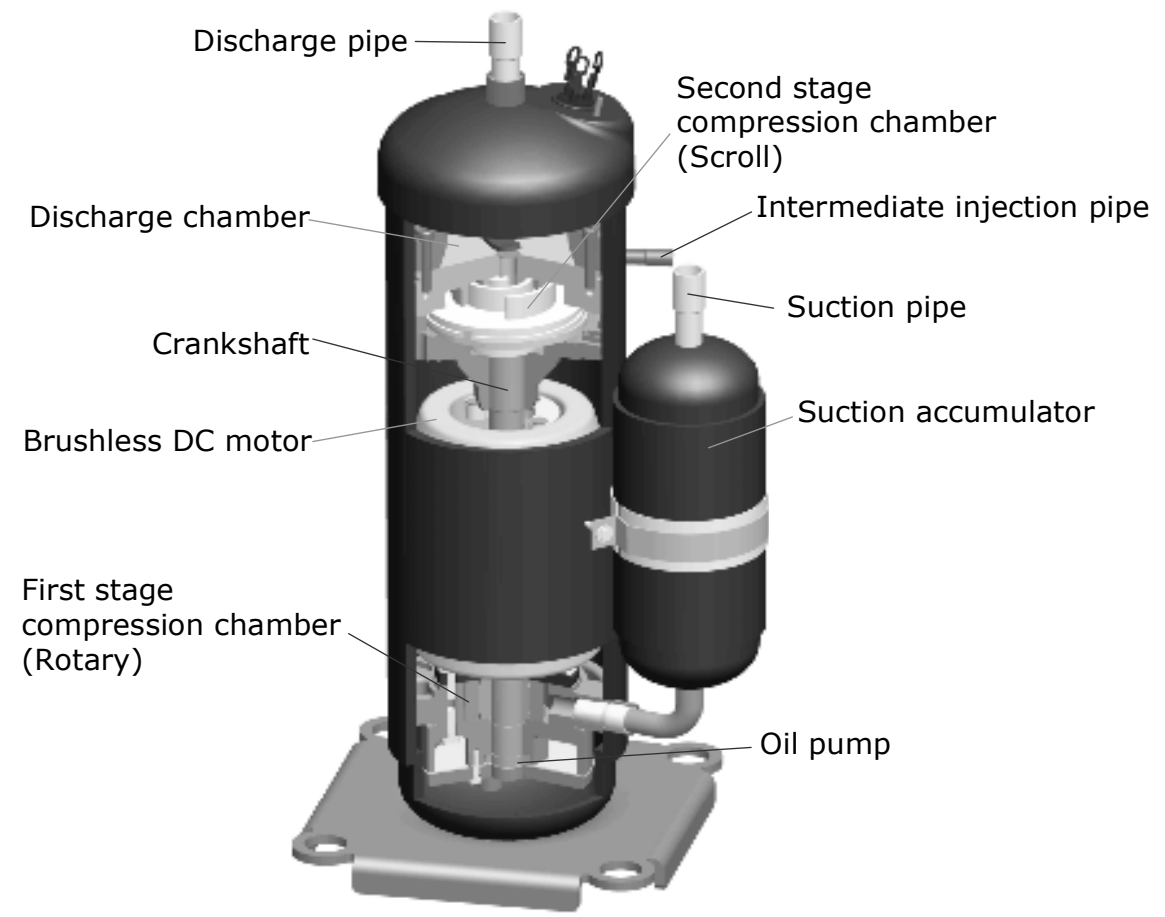

Figure 1: Structure of the new two stage compressor 
A refrigerant gas is introduced the first stage compression chamber through a suction accumulator and compressed to intermediate pressure. The compressed gas is discharged into the shell. Meanwhile, the compressor equips an intermediate gas injection port on the shell. An injection gas is introduced into the shell through the injection port and mixed with the discharged gas of first stage. Then, the gas reaches the second stage compression chamber and compressed to discharge pressure. The compressed gas is discharged to the outside of the compressor through a discharge pipe on the top of the shell.

\section{EFFICIENCY IMPROVEMENT}

In order to verify an efficiency improvement, performance tests of the developed new compressor and conventional prototype single stage scroll compressor was carried out. Here, compressor efficiency $\eta$ of two stage compressor with intermediate gas injection is defined by the following equation.

$$
\eta=\frac{W_{t h}}{W}=\frac{\Delta h_{1} G_{1}+\Delta h_{2} G_{2}}{W}=\frac{\left(h_{1 d}-h_{1 s}\right) G_{1}+\left(h_{2 d}-h_{2 s}\right) G_{2}}{W}
$$

Where, $\mathrm{W}_{\text {th }}$ is theoretical compression power, $\mathrm{W}$ is measured total power input, $\mathrm{G}$ is refrigerant mass flow and $\mathrm{h}$ is enthalpy. Subscripts 1 and 2 mean first and second stage respectively, and subscripts $\mathrm{s}$ and $\mathrm{d}$ mean suction and discharge respectively as shown in Figure2. Suction enthalpy in the second stage $h_{2 s}$ is calculated by the following.

$$
h_{2 s}=\frac{h_{1 d} G_{1}+h_{i n j} G_{i n j}}{G_{1}+G_{i n j}}
$$

Discharge enthalpies $\mathrm{h}_{1 \mathrm{~d}}, \mathrm{~h}_{2 \mathrm{~d}}$ are calculated under the assumption of isentropic compression.

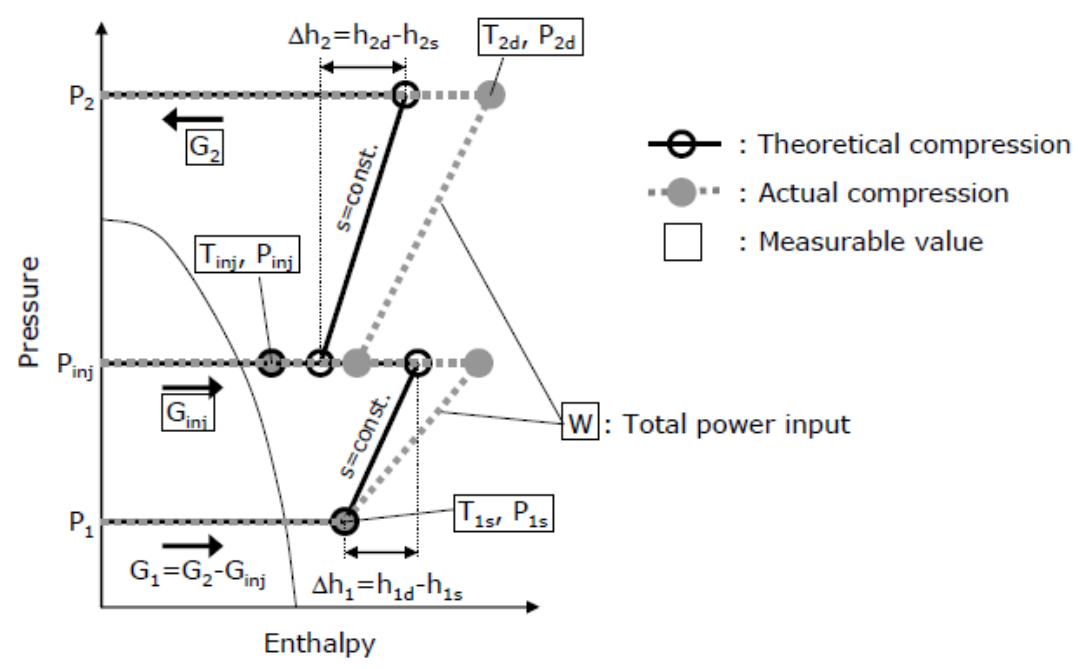

Figure 2: Definition of compressor efficiency

For efficiency improvement in the developed compressor, authors measured cylinder pressure in each stage using a prototype compressor which equips pressure sensors mounted on the compressor chambers. Also, authors tried to extract some improvement by loss classification using the obtained pressure waveform. Figure 3 shows the loss ratio on rated condition $(\mathrm{Pd} / \mathrm{Ps}=3)$. It is found that the indicative loss is about 3 times larger than the mechanical loss. This result revealed that the leakage loss of scroll constitute more than half of total indicative loss, and it is necessary for efficiency improvement of the developed compressor to reduce the leakage loss in the scroll chamber. In order to reduce the leakage loss, leakage clearances in the scroll chamber were optimized considering pressure 


\section{2, Page 5}

and thermal deformation. Figure 4 compares pressure waveform after optimization of the clearances with the original one. $6 \%$ reduction of leakage loss was archived by the optimization.

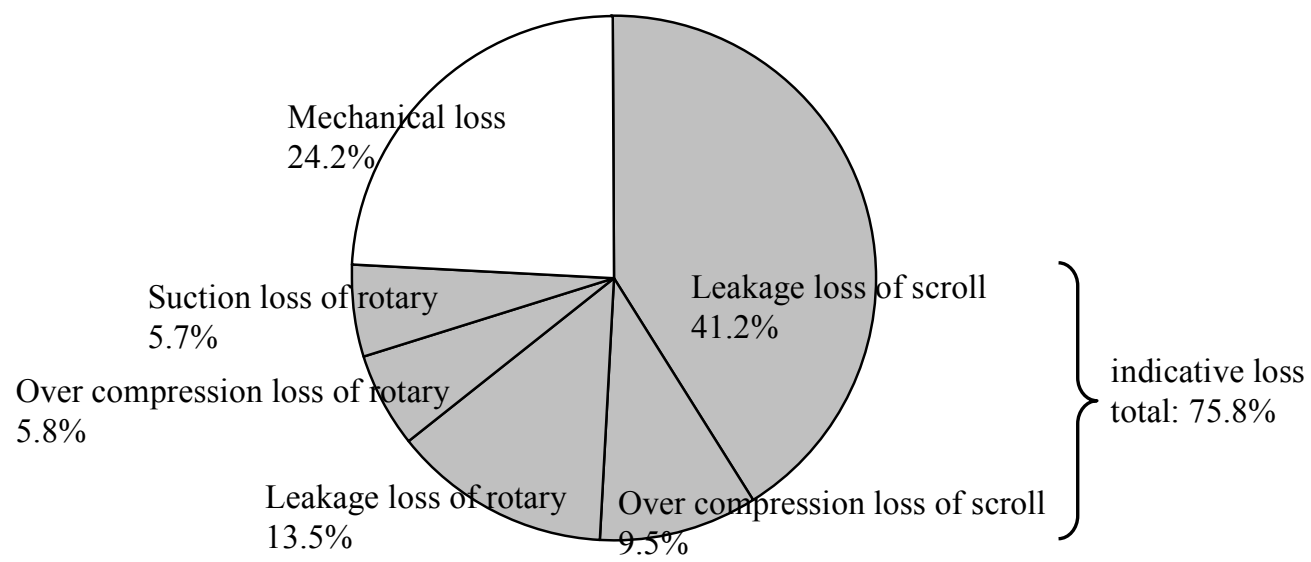

Figure 3: loss ratio

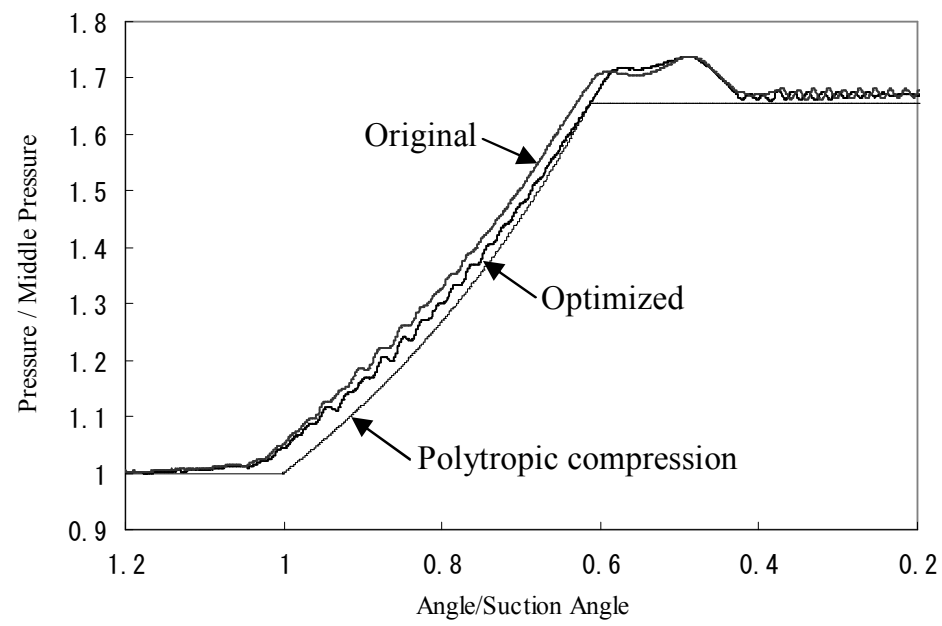

Figure 4: Pressure waveform of scroll chamber

Figure 5 shows efficiency variation against operating pressure ratio in the developed two stage new compressor and conventional prototype single stage scroll compressor. In this figure, vertical scale is normalized by the efficiency of conventional compressor on rated condition. For the conventional compressor, the efficiency drops with increasing of operating pressure ratio due to an increase in leakage and mechanical losses. On the other hand, for the developed new compressor, there is little decline in efficiency with increasing of operating pressure ratio because of employment of the two stage compression mechanism. The developed new compressor resulted in $15 \%$ improvement of efficiency on rated condition and more than 30\% improvement on high pressure ratio condition as against conventional single stage scroll compressor.

Figure 6 compares heating capacity and COP between two stage intermediate gas injection system with the developed new compressor and single stage system with the conventional scroll compressor. In this figure, the heating capacity and the COP is calculated from theoretical value in each refrigeration cycle and measured compressor efficiencies as shown in Figure 2. Ratio of improvement in heating capacity as against single stage cycle with the conventional compressor increases as ambient air temperature decreases because the gas flow rate of gas 
cooler is increased due to an increase of intermediate gas injection. Furthermore, ratio of improvement in COP increases substantially with decrease of ambient air temperature because of the improvement of compressor efficiency in addition to the increase of heating capacity. The developed new compressor resulted in $6 \%$ and $10 \%$ improvement of heating capacity and COP respectively on rated condition (Condition A), and 25\% and over 50\% improvement on deep-frozen condition (Condition D). These results indicate that the developed new compressor has a special advantage for applications operating under high compression ratio such as refrigeration or chilling unit as well as heat pump water heater in cold region.

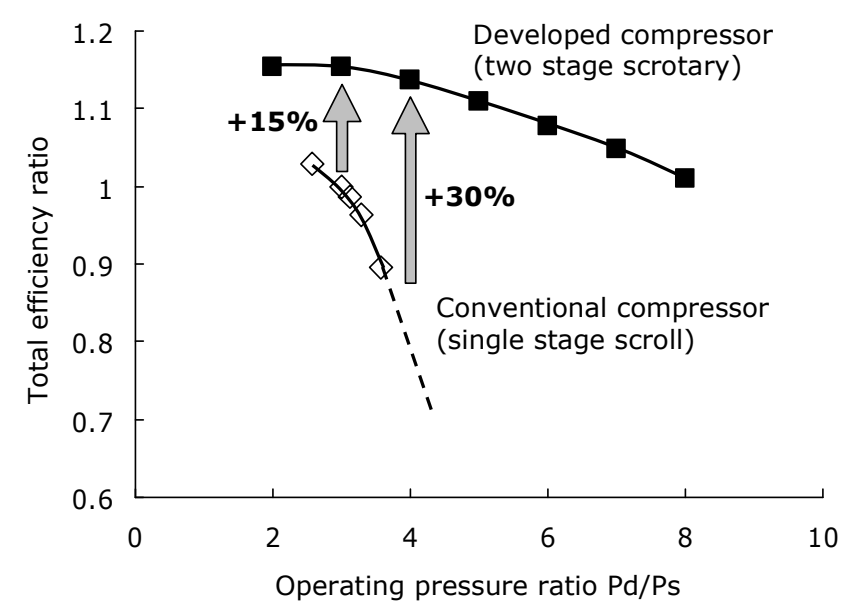

Figure 5: Efficiency variation against operating pressure ratio

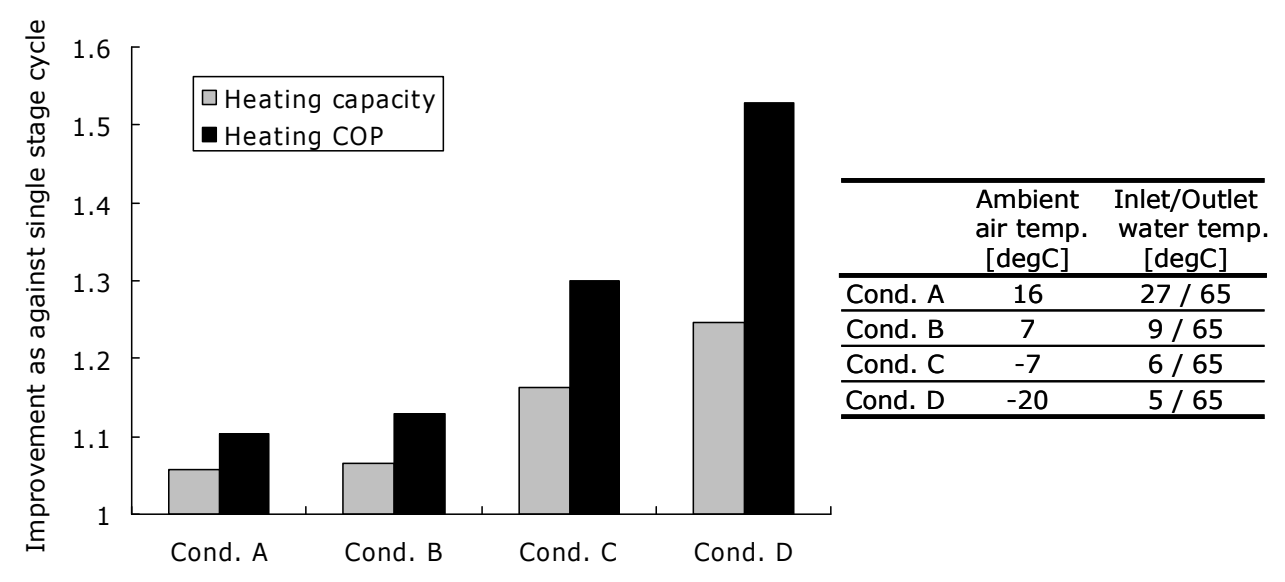

Figure 6: Improvement of heating capacity and COP 


\section{RELIABILITY IMPROVEMENT}

Since CO2 has several times higher pressure difference compared with the conventional HFC, most CO2 compressors that have been developed so far have special efforts such as adoption of a hard coating to sliding surface (Hattori et al., 2008)(Okuda et al., 2009) and reduction of contact pressure in its bearing (Noyama et al., 2004)(Yano et al., 2008) in order to assure their reliability. However, by adopting two stage compression, pressure difference in each stage decreased by about half. As a result, current design approach for HFC compressor can be utilized in the design of mechanical parts in the developed $\mathrm{CO} 2$ compressor with little change.

An proper amount of oil supply to all sliding mechanical parts in both first and second stages is one of the particular requirements for the two stage compressor since the number of mechanical parts that require lubrication becomes twice as many as that in the single stage compressor. Figure 7 shows the flow pathway of oil and refrigerant in the new compressor. The developed compressor equips a positive displacement oil pump at the lower end of the crankshaft in order to supply sufficient oil in every operating condition. The oil pumped up from the oil storage in the bottom of the shell is introduced into the oil channel inside of the crankshaft. After that, the oil is supplied to journal bearings of both stages. In order to keep reliability of the journal bearings, oil distribution ratio in each bearing should be determined properly. In the developed compressor, the dimensions of oil channel to the bearings are optimized based on the required oil amount and pressure drop of the channel. Some of the oil after lubricated the bearings is introduced to the compression chambers and seal leakage clearances. The other is returned to the oil storage.

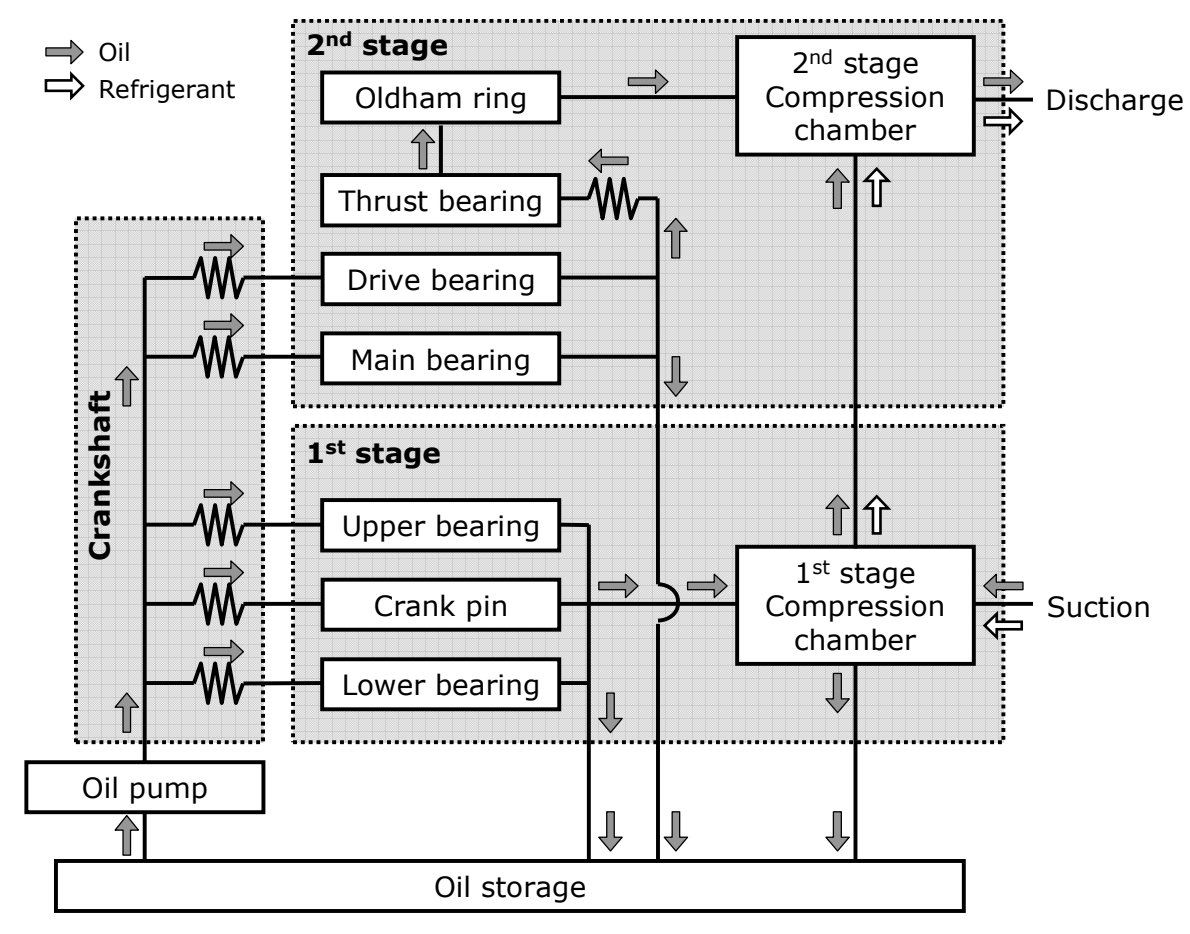

Figure 7: Flow pathway of oil and refrigerant in the new two stage compressor 


\section{APPLICATION OF THE DEVELOPED NEW COMPRESSOR INTO COMMERCIAL HEAT PUMP WATER HEATER}

The developed new compressor is installed on our newly developed commercial heat pump water heater. The developed system has the following features.

- Two stage compression and intermediate gas injection cycle using the developed new compressor are adopted.

- Rated heating capacity is $30 \mathrm{~kW}$ and is sustainable up to $-7 \mathrm{degC}$ ambient air temperature.

- The COP in rated condition reached 4.3.

- $90 \mathrm{degC}$ of hot water supply is available even in the condition of $-25 \mathrm{degC}$ ambient air temperature.

Figure 8 shows variation of heating capacity and COP against ambient air temperature. Since conventional heat pump water heater has a disadvantage that the heating capacity decrease in low ambient temperature condition, there has been a restriction on its installation in cold regions. However, the developed system achieves high heating capacity as well as high COP in low ambient temperature by adopting two stage compression and intermediate gas injection using the high efficiency new compressor.

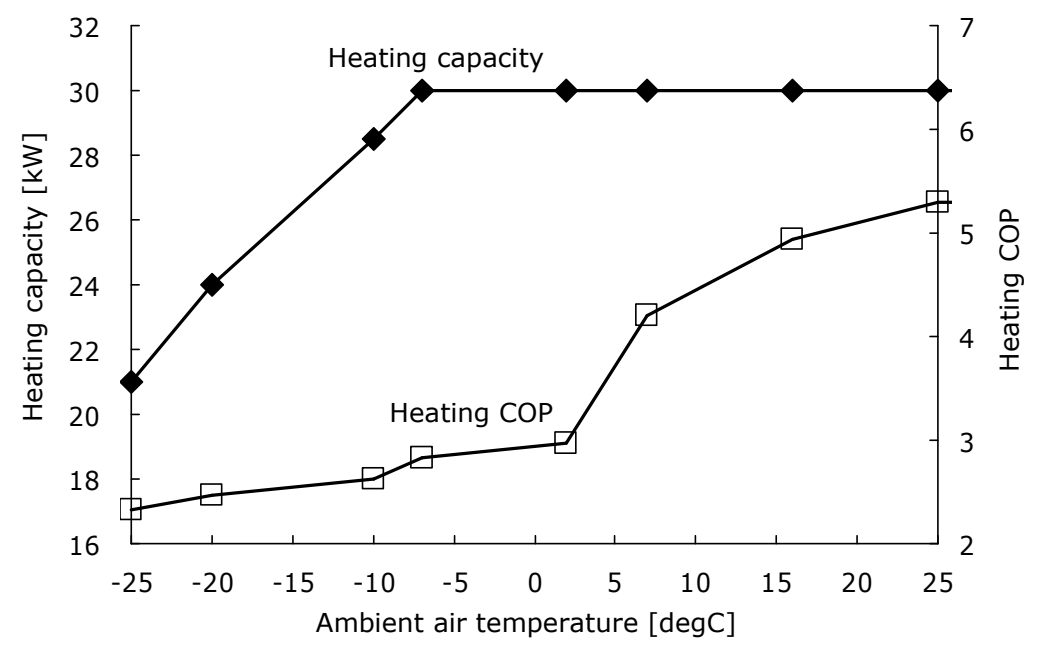

Figure 8: Variation of Heating capacity and COP against ambient air temperature in the developed heat pump water heater

(Inlet/outlet water temperature $=5 / 65 \mathrm{degC}$ )

\section{CONCLUSIONS}

$\mathrm{CO} 2$ two stage compressor for commercial heat pump water heater was developed and the following conclusions were obtained.

- A novel two stage compressor which has both scroll and rotary compression mechanism and an intermediate gas injection was developed.

- The efficiency of the developed new compressor resulted in 15\% improvement of rated condition and more than $30 \%$ improvement on high pressure ratio condition as against conventional prototype single stage scroll compressor.

- The developed new compressor resulted in $6 \%$ and $10 \%$ improvement of heating capacity and COP respectively on rated condition, and $25 \%$ and over $50 \%$ improvement on deep-frozen condition.

- Dimensions of oil channel to the sliding parts in both first and second stages are optimized based on the required oil amount and pressure drop of the channel in order to keep reliability of the developed compressor.

- The developed new compressor is installed on our newly developed commercial heat pump water heater. 


\section{2, Page 9}

\section{REFERENCES}

T. Yokohama, et al., 2008, Developing a two-stage rotary compressor for CO2 heat pump systems with refrigerant injection, Proc. of international compressor engineering conference at Purdue, Purdue University, 1193

N. Hattori, et al., 2008, Wear-less technology for rotary compressor using CO2 refrigerant, Proc. of international compressor engineering conference at Purdue, Purdue University, 1166

K. Okuda, et al., 2009, Heat pump hot-water supply system applying high-efficiency rotary compressor and inverter, Toshiba review, Vol. 64, No. 11

H. Noyama, et al., 2004, Development of CO2 electric driven automotive air-condition system, Proc. of the international symposium on new refrigerants and environmental technology 2004, JRAIA, pp168-171

K. Yano, et al., 2008, Development of large capacity CO2 scroll compressor, Proc. of international compressor engineering conference at Purdue, Purdue University, 1189 